\title{
Role of OCT4 in the Regulation of FSH-Induced Granulosa Cells Growth in Female Mice
}

\author{
Dai Heng, Qiaozhi Wang, Xiaoshu Ma, Ye Tian, Kaili Xu, Xuechun Weng, Xusong Hu, \\ Wenbo Liu and Cheng Zhang*
}

College of Life Science, Capital Normal University, Beijing, China

\section{OPEN ACCESS}

Edited by:

Qiang Weng,

Beijing Forestry University, China

Reviewed by:

Guoliang Xia

China Agricultural University

(CAU), China

Wei Ma,

Capital Medical University, China

Meirong Du,

Fudan University, China

*Correspondence:

Cheng Zhang

zhch8012@163.com

Specialty section:

This article was submitted to

Molecular and Structural

Endocrinology,

a section of the journal

Frontiers in Endocrinology

Received: 08 July 2019 Accepted: 16 December 2019

Published: 10 January 2020

Citation:

Heng D, Wang Q, Ma X, Tian Y, Xu K,

Weng $X, H u X$, Liu W and Zhang $C$ (2020) Role of OCT4 in the Regulation of FSH-Induced Granulosa Cells

Growth in Female Mice.

Front. Endocrinol. 10:915

doi: 10.3389/fendo.2019.00915
As a member of the POU (Pit-Oct-Unc) transcription factor family, OCT4 (Octamer-binding transcription factor 4 ) is associated with the cellular proliferative. However, the roles of OCT4 in regulating the transition from preantral follicle to early antral follicle are still remains unclear. To evaluate the effect of OCT4 on cellular development in ovary, mice were injected with eCG in vivo or granulosa cells were co-cultured with FSH in vitro. The results showed that eCG up-regulated ovarian OCT4 expression. Meanwhile, OCT4 expression in granulosa cells was also up-regulated by FSH, and knockdown of OCT4 by siRNA significantly decreased FSH-induced cellular viability. Moreover, gonadotropin increased p-GSK3 $\beta$ (Glycogen synthase kinase 3-beta) level, $\beta$-catenin expression and its translocation to nuclear in ovarian cells. In addition, the inhibition of GSK3 $\beta$ activity by CT99021 significantly increased the expression of $\beta$-catenin and OCT4 in granulosa cells. And knockdown $\beta$-catenin by siRNA dramatically abolished FSH-induced OCT4 expression and cellular development. Furthermore, FSH-induced the phosphorylation of GSK3 $\beta$, expression of $\beta$-catenin and OCT4, and translocation of $\beta$-catenin were mediated by the PI3K/Akt pathway. Taken together, the present study demonstrates that FSH regulated OCT4 expression via GSK3 $\beta / \beta$-catenin pathway, which was mediated by the PI3K/Akt pathway. And these regulations are involved in ovarian cell development.

Keywords: FSH, OCT4, GSK3 $\beta, \beta$-catenin, granulosa cells, mice

\section{INTRODUCTION}

Mammalian ovarian follicular development is a highly selective process that is complex and accompanied by cell proliferation, differentiation, or apoptosis (1-6). The transition from preantral follicle to early antral follicle is a critical period for follicular development (development vs. atresia), which is responsive to gonadotropin (4). Our previous study show that FSH increases preantral follicle growth in vitro (7). Moreover, FSH significantly promotes granulosa cell proliferation, inhibits cellular apoptosis, which is mediated by the phosphatidylinositol 3-kinase (PI3K)/protein kinase B (Akt) pathway $(8,9)$. However, the precise mechanisms of FSH-induced cellular growth are still unclear.

Octamer-binding transcription factor 4 (OCT4) is known as a stem-cells marker, which is closely related with the various cells development (10-14). OCT4 can promote ovarian mesenchymal cell proliferation and increase the potency to promote oogenesis, and regulates the development of membrane cells and granulosa cells (15). It has been reported that OCT4 is detected in oocyte and granulosa cell of growing follicles, and plays important roles in oocyte growth and 
meiosis $(14,16,17)$. Moreover, the expression of OCT4 in ovary is closely related to the estrous cycle, which is also regulated by gonadotropin (18-20). However, the precise roles and mechanisms of OCT4 during the early follicular development are not known.

It has been reported that $\beta$-catenin is very important to the stem cell proliferation and hair follicle regeneration by regulating OCT4 expression $(21,22)$. The $\mathrm{Wnt} / \beta$-catenin signaling is involved in the regulations of follicular development $(23,24)$, which is regulated by GSK3 $\beta$. GSK3 $\beta$, as an enzyme, regulates the stabilization of $\beta$-catenin and its translocation to the nucleus (25). And GSK $3 \beta$ also regulates cell development, energy metabolism, gene transcription, cell cycle progression, proliferation, and apoptosis in vivo $(26,27)$. Moreover, several reports have shown that the activation of phosphatidylinositol 3-kinase (PI3K)/Akt can phosphorylate GSK3 $\beta$ at Ser9, which leads to the inactivation of GSK3 $\beta$, and then inhibit the degradation of $\beta$-catenin (2831 ). And the accumulation and nuclear translocation of $\beta$-catenin sustain the transcription of stemness genes including OCT4 (17). Whether these pathways are indeed regulated by FSH in granulosa cells are not known.

In this study, we investigated the cellular and molecular mechanisms by which gonadotropin regulate OCT4 expression during the preantral follicle growth. We demonstrated that FSH regulates OCT4 expression, which is related to the GSK3 $\beta / \beta$ catenin pathway. And these responses appeared to be mediated by the PI3K/Akt pathway.

\section{MATERIALS AND METHODS}

\section{Reagents and Antibodies}

All reagents and chemicals used in present study were purchased from Sigma-Aldrich (St. Louis, MO, USA), unless otherwise indicated. M199 was purchased from Gibco Bethesda Research Laboratories (Grand Island, NY, USA). PI3K inhibitor (LY294002) and Akt inhibitor (API-2) were purchased from Selleck (Selleck Chemicals, Houston, TX, USA). The Cell Counting Kit-8 (CCK-8) was used to analyze cell viability, which was purchased from Dojindo (Dojindo, Kumamoto, Japan). Lipofectamine 3000 was purchased from Invitrogen (Invitrogen, Carlsbad, CA). Rabbit polyclonal anti-OCT4 (ab19857), rabbit monoclonal anti- $\beta$-catenin antibody (ab32572), rabbit monoclonal anti-GSK3 $\beta$ antibody (ab3291), rabbit monoclonal anti-Phospho-GSK3 $\beta$ (Ser9) antibody (D3A4), and rabbit polyclonal anti-GAPDH (ab9485) were purchased from Abcam (Abcam, USA). Rabbit monoclonal anti-Phospho-GSK3 $\beta$ (Ser9) antibody (D3A4), rabbit polyclonal anti-phospho-Akt antibody (\#9271) and rabbit polyclonal anti-Akt antibody (\#9272) were from Cell Signaling Technology (Cell Signaling, USA). Horse radish peroxidase (HRP)-conjugated anti-rabbit IgG was from Santa Cruz Biotechnology, Inc. (Santa Cruz, Beijing). Revert Aid

\footnotetext{
Abbreviations: FSH, follicle-stimulating hormone; LH, luteinizing hormone; $\mathrm{GnRH}$, gonadotropin-releasing hormone; $\mathrm{E}_{2}$, estradiol; PI3K, phosphoinositide 3-kinase; OCT4, octamer-binding transcription factor 4; GSK3 $\beta$, glycogen synthase kinase 3-beta gene; FSHR, follicle stimulating hormone receptor; TCF3, transcription factor 3; HPG, hypothalamus-pituitary-gonadal axis.
}

First Strand cDNA Synthesis Kit, TRIzol Reagent were obtained from Thermo Fisher Scientific Inc. (Thermo Scientific, USA), SYBR Green PCR kit was purchased from Bio-Rad (Richmond, CA, USA). PCR primers for OCT4 and 18S rRNA were from Sunbiotech Inc. (Beijing Sunbiotech Co., Ltd. China).

\section{Animal Experiments}

Kunming White female mice (outbreed strain, 21-day old) were purchased from the Beijing Vital Laboratory Animal Technology Co. (Beijing, China). Mice were maintained under constant conditions of temperature $\left(24-26^{\circ} \mathrm{C}\right)$ and humidity $(60 \pm 2 \%)$ with a 12/12-h light/dark cycle and received pathogen-free water and food for maintenance. All animal treatment procedures were in accordance with the Principles of the Care and Use of Laboratory Animals and China Council on Animal Care and were approved by the Institutional Animal Care and Use Committee of Capital Normal University. Mice were injected subcutaneously (s.c.) with 10 international units (IU) of eCG in $100 \mu \mathrm{L}$ of phosphate buffered saline (PBS) containing $0.2 \%(\mathrm{w} / \mathrm{v})$ bovine serum albumin (BSA) or PBS alone. In some experiment, mice were injected subcutaneously with DES (1 mg/day; 3 days), and ovaries were collected at $72 \mathrm{~h}$ after euthanized by cervical dislocation.

\section{Primary Culture of Granulosa Cells}

Granulosa cells were collected by follicular puncture with a 26.5gauge needle. And cell number and viability were estimated by Trypan blue dye-exclusion test. Granulosa cells $\left(9 \times 10^{5}\right.$ per well in six well plate) were plated with $2 \mathrm{ml}$ of M199 medium [supplemented with HEPES $(10 \mathrm{mM})$, streptomycin $(100 \mu \mathrm{g} / \mathrm{ml})$, penicillin $(100 \mathrm{U} / \mathrm{ml})$, and fungizone $(0.625 \mu \mathrm{g} / \mathrm{ml})]$ containing fetal bovine serum $(10 \%$, wt/vol) under a humidified atmosphere of $95 \%$ air and $5 \% \mathrm{CO}_{2}$. The cells were treated with $\mathrm{FSH}$ $(100 \mathrm{ng} / \mathrm{ml})$ for different duration. In some experiments, cells were treated with OCT4 activator O4I2 $(12.5 \mu \mathrm{M})$ for $24 \mathrm{~h}$ or pretreated with PI3K inhibitor LY294002 $(10 \mu \mathrm{M})$, Akt inhibitor API-2 $(10 \mu \mathrm{M}) 1 \mathrm{~h}$ or GSK3 $\beta$ inhibitor CT99021 $(15 \mu \mathrm{M}) 12 \mathrm{~h}$ before hormone treatment, respectively.

\section{RNA Interference}

The siRNA was transfected into granulosa cells according to the instruction of the manufacturer's protocol. Granulosa cells were transfected $(48 \mathrm{~h})$ with OCT4 or $\beta$-catenin siRNA (GenePharma) and scrambled sequence control (GenePharma), using Lipofectamine 3000 (Invitrogen) according to manufacturer's instructions.

\section{Protein Extraction and Western Blotting}

Western blotting analysis was performed as described previously $(32,33)$. Briefly, the homogenate was centrifuged $(14,000 \times$ g, $4^{\circ} \mathrm{C}, 30 \mathrm{~min}$ ) for collecting the supernatant after ovaries homogenization. For granulosa cells, whole-cell lysates were prepared by incubating cell pellets in lysis buffer. Meanwhile, Nuclear and Cytoplasmic Protein Extraction Kit (Beyotime P0027) was used to collect the nuclear and cytoplasmic protein. Thirty microgram (depending on individual experiments) of cell lysates were subjected to SDS-PAGE with $4.5 \%$ stacking and $10 \%$ 
separating gels. Proteins were electrophoretically transferred to nitrocellulose membrane. And then, the membrane were incubated $\left(4^{\circ} \mathrm{C}\right.$, overnight $)$ with diluted primary antibody [polyclonal anti-OCT4 (1:1,000), polyclonal anti-GSK3 $\beta$ $(1: 5,000)$, polyclonal anti-phospho-GSK3 $\beta(1: 1,000)$, polyclonal anti- $\beta$-catenin $(1: 5,000)$, polyclonal anti-Akt $(1: 1,000)$, polyclonal anti-phospho-Akt (Ser473) (1:1,000) or GAPDH (1:10,000)], respectively, followed by HRP-conjugated secondary antibody (1:1,000-1:10,000; 1.5 h, RT). Peroxidase activity was visualized

TABLE 1 | Primer sequence used for real-time quantitative PCR

\begin{tabular}{|c|c|c|c|c|}
\hline $\begin{array}{l}\text { Target } \\
\text { gene }\end{array}$ & $\begin{array}{c}\text { GenBank } \\
\text { accession No. }\end{array}$ & Primer sequence & $\begin{array}{l}\text { Product } \\
\text { Size, bp }\end{array}$ & $\begin{array}{c}\text { Annealing } \\
\text { temperature, } \\
{ }^{\circ} \mathbf{C}\end{array}$ \\
\hline OCT4 & NM_013633 & $\begin{array}{l}\text { F:5' -GAGGAGTCC } \\
\text { CAGGACATGAA-3' } \\
\text { R:5'-AGATGGTGG } \\
\text { TCTGGCTGAAC-3' }\end{array}$ & 122 & 62 \\
\hline 18S rRNA & NM_008084.3 & $\begin{array}{l}\text { F:5' - TGGCCTTCC } \\
\text { GTGTTCCTAC-3' } \\
\text { R:5' - GAGTTGCTG } \\
\text { TTGAAGTCGCA-3' }\end{array}$ & 178 & 60 \\
\hline
\end{tabular}

with the ECL kit according to the manufacturer's instructions. Protein content was determined by densitometrically scanning the exposed $x$-ray film. Immunoreactions signals were analyzed using gel-pro Analyzer 4.0.

\section{Real-Time Quantitative PCR Analysis}

The cDNA was synthesized form $0.2 \mu \mathrm{g}$ total RNAs which were extracted with TRIzol Reagent (Invitrogen, Carlsbad, CA). And the mRNA abundance of target genes was analyzed by real-time PCR and normalized to $18 \mathrm{~S}$ rRNA. Specific primer pairs used in the experiments are listed in Table 1. Data were analyzed by the $2^{-\Delta \Delta \mathrm{CT}}$ method (34).

\section{Analysis of Cell Viability}

The cell viability was measured by Cell Counting Kit-8 (Dojindo, Kumamoto, Japan) (35). Briefly, CCK-8 solution (10 $\mu \mathrm{L})$ was added to each well after treatment, and the cells were incubated for an additional $2 \mathrm{~h}$ at $37^{\circ} \mathrm{C}$. The $\mathrm{OD}$ values were recorded using a microplate reader at $450 \mathrm{~nm}$. And the mean OD values for each treatment were used as the index of cell viability.

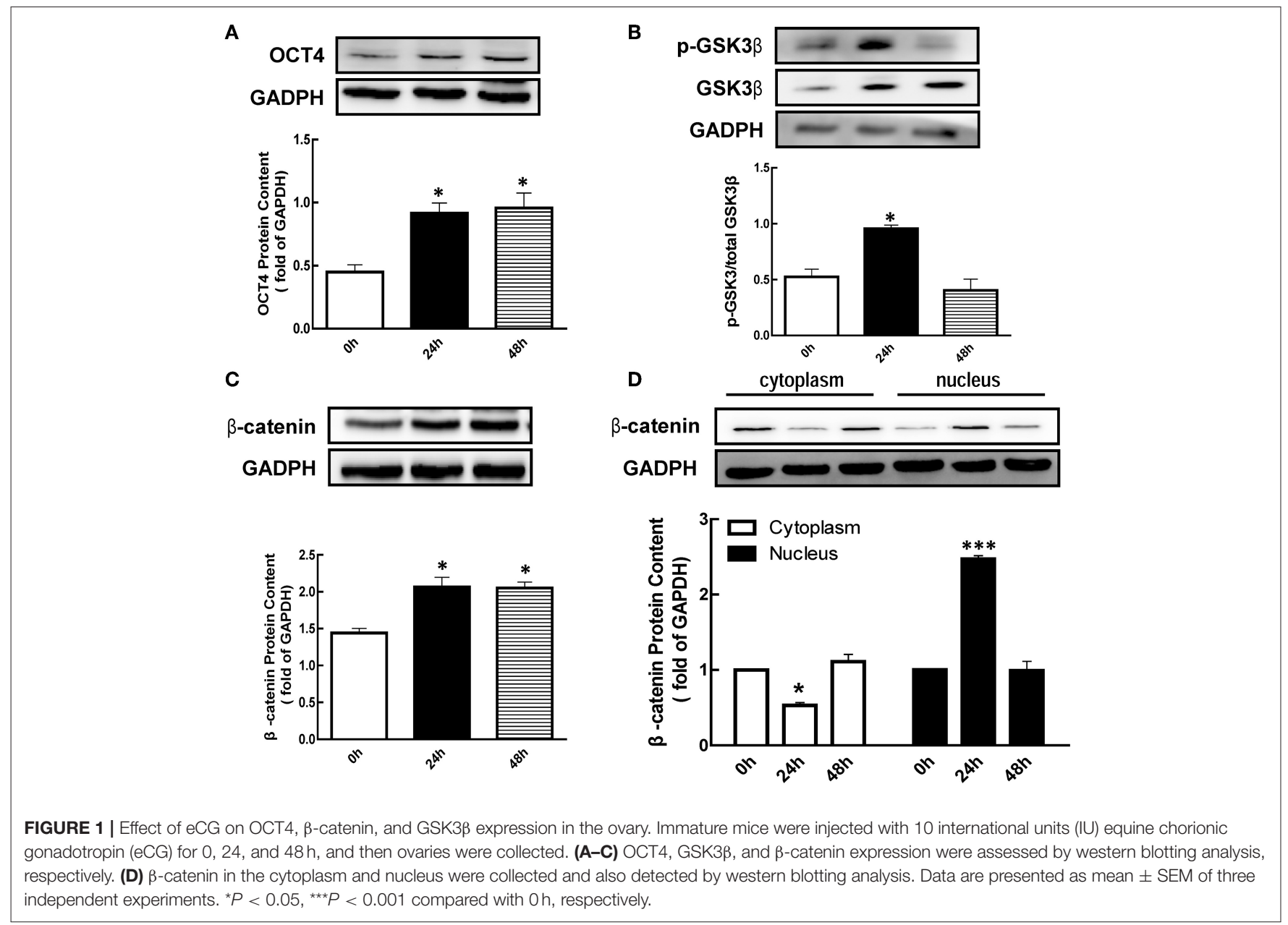




\section{Immunofluorescence Cell Staining}

Granulosa cells were cultured in poly-D-lysine (0.05\% wt/vol; Sigma) coated 8-well glass culture slides (Becton, Dickinson and $\mathrm{Co}$ ) for immunofluorescence analysis. After treatment, cells were fixed in $4 \%$ paraformaldehyde in PBS for $30 \mathrm{~min}$, permeabilized with $0.1 \%$ Triton $\mathrm{X}-100$ in PBS for $5 \mathrm{~min}$, and then blocked with 5\% BSA in PBS for $30 \mathrm{~min}$. And then, cells were incubated with monoclonal anti- $\beta$-catenin (1:200 dilution in blocking solution) at $4^{\circ} \mathrm{C}$ for overnight. After washing three times with PBS, cells were then incubated with Alexa Fluor 488-conjugated secondary antibody (1:100 dilution in blocking solution; Jackson ImmunoResearch, Lancaster, PA) for $1.5 \mathrm{~h}$ at room temperature. After incubating with DAPI, the coverslips were mounted on object slides using fluorescentmounting medium. Immunofluorescence was visualized using an immunofluorescence microscope (Olympus BX51), and images were recorded by using Laser Scanning Microscope LSM 780 (ZEISS, Jena, Germany).

\section{Statistical Analysis}

All the results are expressed as means \pm SEM of at least three independent experiments. The statistical differences between treatments were calculated with unpaired or $t$-test, one-way or two-way (repeated-measure) ANOVA (Prism 5.0 statistical software; GraphPad Software, Inc., San Diego, CA). When significant differences were found, means were compared by the Bonferroni post-test. $P<0.05$ were considered to be statistically significant.

\section{RESULTS}

\section{Effects of eCG on GSK3 $\beta, \beta$-Catenin, and OCT4 Expression}

To investigate the effect of eCG on the expression of p-GSK3 $\beta$, $\beta$ catenin, and OCT4 protein in mice ovary, eCG were injected for 24 or $48 \mathrm{~h}$, respectively, and determined ovarian OCT4 content using western blotting analysis. As shown in Figure 1A, the

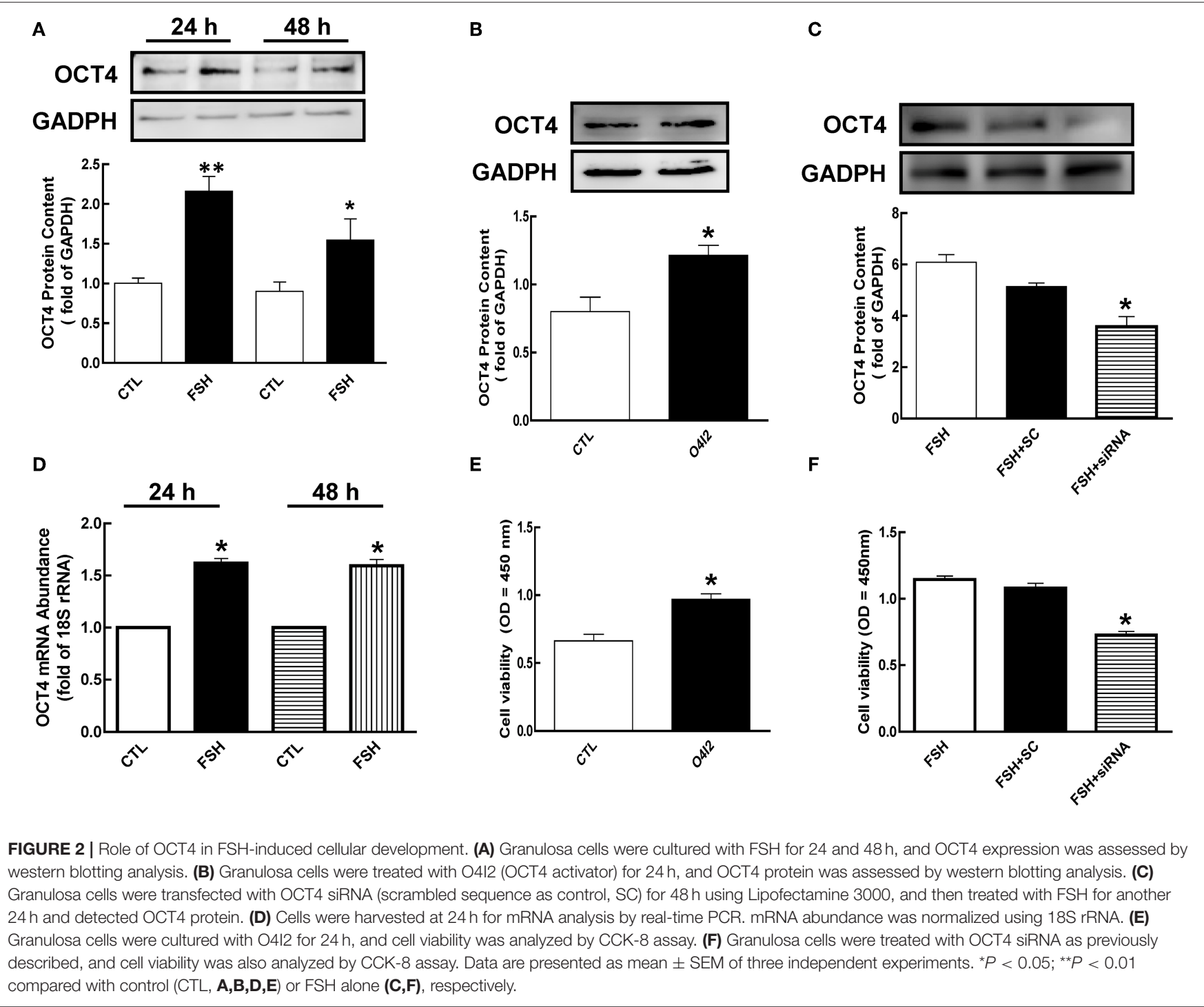


expression of OCT4 was significantly increased 2.04 and 2.13fold at 24 and $48 \mathrm{~h}$ after eCG treatment $(p<0.05)$, respectively.

Meanwhile, we also detected the p-GSK3 $\beta$ (Ser9) level after eCG treatment. The results showed that the level of $\mathrm{p}-\mathrm{GSK} 3 \beta$ (Ser9) was significantly increased 1.82 -fold at $24 \mathrm{~h}$ (Figure 1B, $p<0.05)$ after eCG treatment, while there is no significant difference at $48 \mathrm{~h}$ (Figure 1B). As shown in Figure 1C, the level of $\beta$-catenin was significantly increased 1.43 and 1.42 -fold at 24 and $48 \mathrm{~h}$ after eCG treatment $(p<0.05)$, respectively. In addition, eCG significantly increased $\beta$-catenin translocation from the cytoplasmic to the nuclear at $24 \mathrm{~h}$ (Figure 1D, $p<0.001$ ).

\section{Effects of OCT4 on FSH-Induced Granulosa Cell Development}

To determine whether FSH regulates the expression of OCT4, we cultured granulosa cells with FSH for 24 or $48 \mathrm{~h}$. As shown in Figure 2A, FSH significantly increased OCT4 expression [2.15 $(24 \mathrm{~h})$ and 1.72 -fold $(48 \mathrm{~h}), p<0.05]$. To better understand whether OCT4 content is regulated at the mRNA level by hormone, we determined OCT4 mRNA abundance using realtime PCR analysis. Granulosa cells cultured with FSH for $24 \mathrm{~h}$ had higher mRNA levels compared to those cultured without FSH (Figure 2D, $p<0.05$ ). Moreover, the expression of OCT4 mRNA was also significantly changed after FSH treatment for $48 \mathrm{~h}$. These results suggest that the regulation of OCT4 expression in granulosa cells by FSH occurs at the transcription level or via translational processing.

To investigate the function of OCT4 in granulosa cell development, we cultured cells with OCT4 activator (O4I2) or siRNA with and without FSH. As shown in Figures 2B,C, OCT4 protein content was significantly increased by O4I2 ( $p$ $<0.05)$. Meanwhile, O4I2 significantly induced cellular viability compared that with the control group (Figure 2E, $p<0.05$ ). In contrast, cellular viability was significantly attenuated by OCT4 knockdown (Figure 2F, $p<0.05$ ).

\section{$\beta$-Catenin Mediated FSH Induced OCT4 Expression}

It has been reported that $\beta$-catenin is a bifunctional protein as an intracellular signal transduction. To determine whether $\beta$ catenin is regulated by hormone, granulosa cells were co-cultured with $\mathrm{FSH}$ for $24 \mathrm{~h}$. We noticed that $\beta$-catenin protein levels were

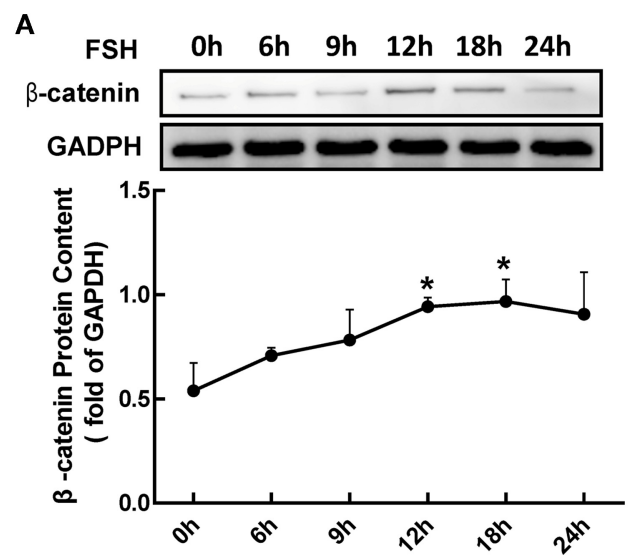

B

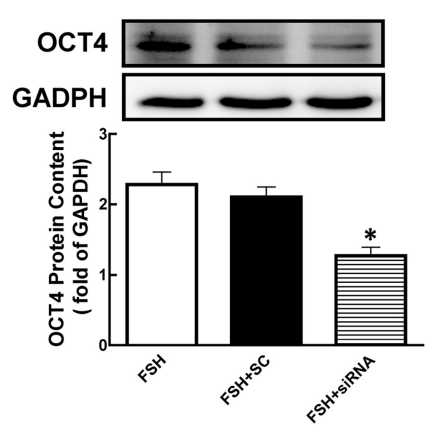

D $\beta$-catenin DAPI Merge
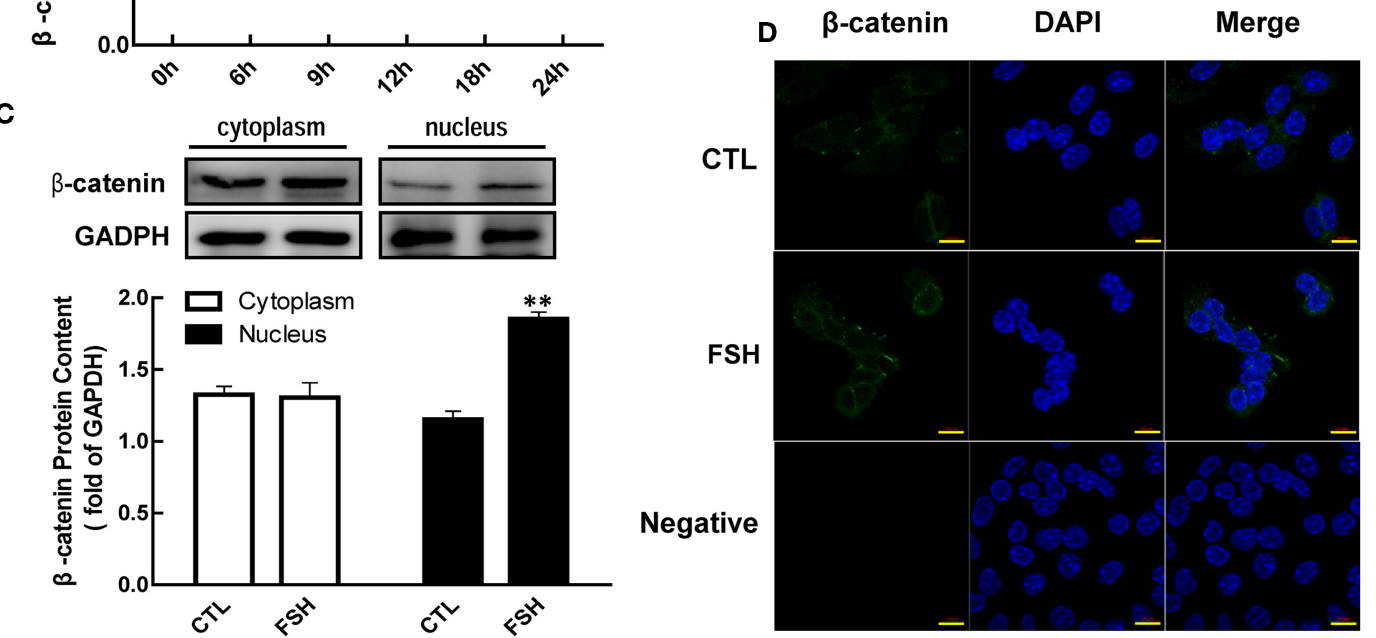

FIGURE 3 | Role of $\beta$-catenin in FSH-induced OCT4 expression. (A) Granulosa cells were cultured with FSH for different duration, and $\beta$-catenin expression was assessed by western blotting analysis. (B) Granulosa cells were transfected with $\beta$-catenin siRNA (scrambled sequence as control, SC) for $48 \mathrm{~h}$ using Lipofectamine 3000 , and then treated with FSH for another $24 \mathrm{~h}$. OCT4 protein was assessed by western blotting analysis. (C) Granulosa cells were cultured with FSH for $18 \mathrm{~h}$, and $\beta$-catenin expression in the cytoplasm and nucleus were assessed. (D) FSH induced the shift of $\beta$-catenin distribution to the nucleus, which was detected by immunofluorescence. Data are presented as mean \pm SEM of three independent experiments. ${ }^{\star} P<0.05$; ${ }^{\star \star} P<0.01$ compared with 0 h (A), FSH alone (B), or control (CTL, C), respectively. Bar, $10 \mu \mathrm{m}$. 


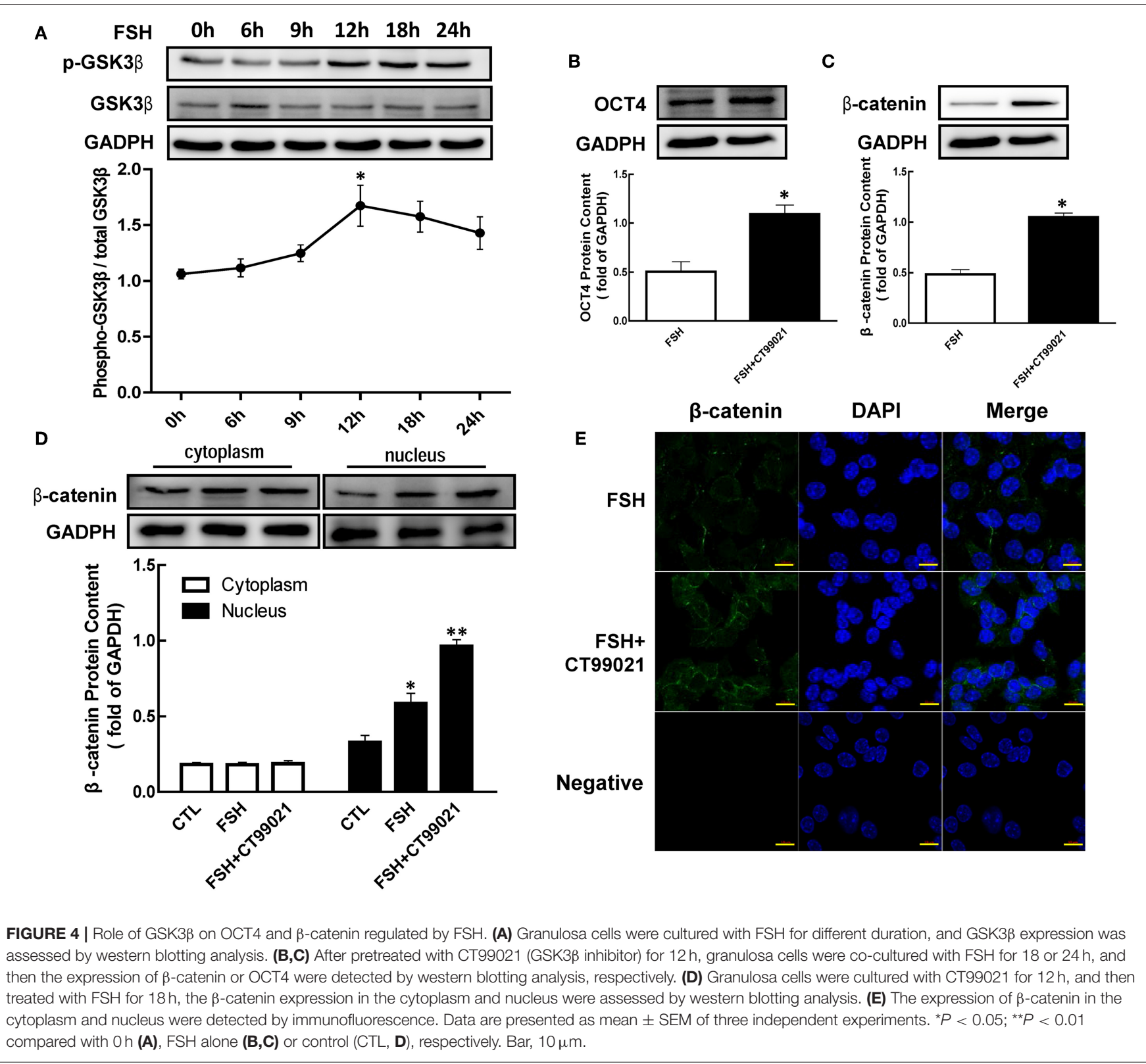

significantly enhanced by FSH from 1.75 (12 h) to 1.80 (12 h)fold (Figure 3A, $p<0.05$ ). Moreover, FSH also significantly increased $\beta$-catenin translocation from the plasma to nucleus (Figure 3C, $p<0.01$ ). These results were also confirmed by immunofluorescence cell staining (Figure 3D).

To further determine whether $\beta$-catenin is essential for FSH-induced OCT4 expression, we applied siRNA to knockdown $\beta$-catenin expression. While OCT4 protein content was up-regulated by the presence of $\mathrm{FSH}$, this effect was significantly attenuated 1.79 -fold by $\beta$-catenin knockdown (Figure 3B, $p<0.05$ ).

\section{Role of GSK3 $\beta$ in FSH Induced $\beta$-Catenin and OCT4 Expression}

To verify the hypothesis that regulations of $\beta$-catenin and OCT4 by hormone were mediated by phosphorylating GSK3 $\beta$
(Ser9), we cultured granulosa cells with FSH, and the content of p-GSK3 $\beta$ were detected by western blotting. As shown in Figure 4, the expression of p-GSK3 $\beta$ (Ser9) was increased with the duration of treatment, and reaching a peak at $12 \mathrm{~h}$ after FSH treatment with a maximum increase of 1.58 -fold (Figure 4A, $p<0.05$ ).

To determine the role of GSK3$\beta$ in hormone-induced $\beta$ catenin and OCT4 expression, granulosa cells were pretreated with CT99021 (GSK3 $\beta$ activity inhibitor) for $12 \mathrm{~h}$, and then treated with FSH for another 18 or $24 \mathrm{~h}$. The results showed that the expression of $\beta$-catenin (Figure 4C, $p<0.05$ ) and OCT4 (Figure 4B, $p<0.05$ ) induced by FSH were significantly enhanced by CT99021. Moreover, CT99021 also increased FSHinduced translocation of $\beta$-catenin by 1.65 -fold, which was also confirmed by immunofluorescence results (Figures 4D,E, $p<$ 0.05; $p<0.01)$. 

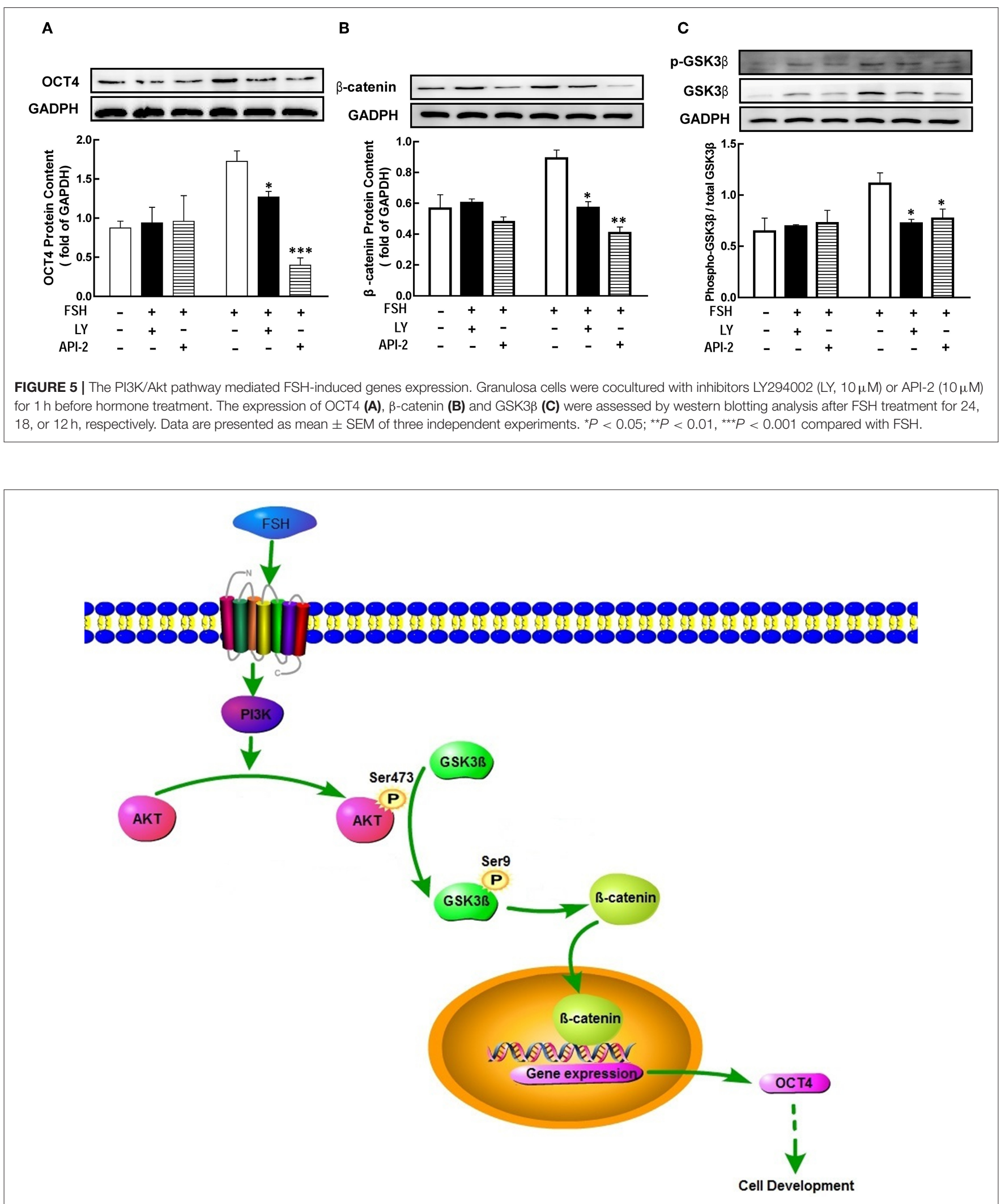

FIGURE 6 | Schematic diagram of the roles of FSH on OCT4 expression. 


\section{Involvement of the PI3K/Akt Pathway in FSH-Induced Genes Expression}

Previous studied had showed that FSH promoted granulosa cells development through PI3K/Akt pathway $(8,9)$. To determine whether PI3K/Akt signaling is necessary for FSHmediated OCT4 expression, we applied LY294002 or API$21 \mathrm{~h}$ before FSH treatment. The results showed that the level of OCT4 was significantly lower than in the group untreated with inhibitors (Figure 5A, $p<0.05$; $p<0.01$ ). The expression of $\beta$-catenin or GSK3 $\beta$ after hormones treatment for 18 or $12 \mathrm{~h}$ were also detected, respectively. The same effects were also showed on $\beta$-catenin and $\mathrm{p}$-GSK3 $\beta$ expression (Figures 5B,C, $p<0.05$ ).

\section{DISCUSSION}

In the present study, we have demonstrated that FSH-induced granulosa cells development through up-regulating OCT4 expression in mice. These responses are mediated by p-GSK3 $\beta$ (Ser9), $\beta$-catenin expression, and translocation. Moreover, the activated PI3K/Akt pathway is also involved in these regulations. To the best of our knowledge, it is the first study to prove that OCT4 plays a crucial role in FSH-induced development in granulosa cells at the preantral to early antral transition stage of follicles.

It is well-known that gonadotropin is important for follicle development, which regulates OCT4 expression and functions in ovary (19). As a transcription factor, OCT4 is involved in the regulation of many genes. In the present study, the expression of ovarian OCT4 was increased after treatment, which is consistent with the previous study (20). Meanwhile, the expression of OCT4 in granulosa cells was also significantly increased by FSH. Knockdown of OCT4 expression by siRNA decreased FSH-induced cell growth, which indicates OCT4 is important to the granulosa cell development. Moreover, FSH increases ovarian cells growth by regulating OCT4 expression, which is possibly mediated by FSHR (Follicle stimulating hormone receptor). It has been reported that both FSHR and OCT4 are expressed in the oocyte of primordial follicle. And the co-localization of FSHR and OCT4 are changed along with follicular growth, which are decreased in oocyte and increased in peripheral granulosa cells in growing follicles (36).

The previous reports show that $\beta$-catenin is very important to the stem cell proliferation (22) and hair follicle regeneration (21) by regulating OCT4 expression. It is possible that FSH-induced OCT4 expression is mediated by $\beta$-catenin since $\beta$-catenin is negatively related to follicular atresia (37). The present study showed that $\beta$-catenin was significantly increased in ovary, and then was transported from the cytoplasm to the nucleus after eCG treatment. The patterns are similar with that eCG-induced OCT4 expression in vivo. The results in granulosa cells in vitro confirm the hypothesis that FSH increased $\beta$-catenin expression and translocation to nuclear, which are essential to OCT4 expression. Moreover, the regulations on follicular development by $\beta$-catenin may be also mediated by regulating estrogen biosynthesis since $\beta$-catenin is a transcriptional regulator of CYP19A1 (38).

It is also well-known that $\beta$-catenin is degraded after forming a complex with the activated GSK-3 $\beta$ (39). GSK3 $\beta$, as a serine/threonine kinase of the Wnt/ $\beta$-catenin pathway, is a negative regulator of $\mathrm{Wnt}$ signaling, which phosphorylates $\beta$ catenin residues, thereby degrading $\beta$-catenin via proteasome (40). However, once GSK-3 $\beta$ is phosphorylated to an inactive form (41) (Ser9), $\beta$-catenin is transferred to the nucleus without degradation and start to transcript $(43,44)$. After interaction with TCF3 (Transcription factor 3 ), nuclear $\beta$-catenin induce the expression of the plasticity factors including OCT4, which in turn promotes hair follicle regeneration (21). Our results showed that the expression of p-GSK3 $\beta$ (Ser9) in ovary is significantly increased after eCG treatment in vivo, which was accompanied by the increased $\beta$-catenin expression. Moreover, FSH increased $\mathrm{p}$ GSK3 $\beta$ level and $\beta$-catenin expression in granulosa cells in vitro. It is possible that the increased intracellular $\beta$-catenin-induced by gonadotropin is due to the phosphorylation of GSK3 $\beta$ at Ser9 as the inactive form in the present study. Moreover, gonadotropin also increased the translocation of $\beta$-catenin from the cytoplasm to the nucleus. In addition, FSH-induced OCT4 expression was attenuated by LY294002 and API-2, respectively. The results indicate that the regulation of hormone on OCT4 is mediated by the PI3K/Akt pathway. It is consistent with the previous reports that the activated Akt inactivates GSK3 $\beta$ and inhibits $\beta$-catenin degradation by phosphorylating GSK3 $\beta$ at Ser9 $(28-31,42)$.

In conclusion, our findings demonstrate that OCT4 is a novel positive regulator for the granulosa cell development in the early stage of follicles. As indicated by the model (Figure 6), $\mathrm{FSH}$ induces the expression of OCT4 in granulosa cells through GSK $3 \beta / \beta$-catenin pathway and promotes cellular development, and these regulatory processes are all mediated by the PI3K/Akt signaling pathway. The results enhance our understanding of the role of OCT4 in ovarian cells.

\section{DATA AVAILABILITY STATEMENT}

All datasets generated for this study are included in the article/supplementary material.

\section{ETHICS STATEMENT}

The animal study was reviewed and approved by Institutional Animal Care and Use Committee of Capital Normal University.

\section{AUTHOR CONTRIBUTIONS}

$\mathrm{DH}$ and QW performed the experiments and analyzed the data. $\mathrm{CZ}, \mathrm{XM}$, and $\mathrm{DH}$ interpreted the results of the experiments. $\mathrm{XW}$ and KX prepared the figures. YT, WL, KX, and $\mathrm{XH}$ contributed to the discussion. $\mathrm{CZ}$ designed the research and wrote the manuscript. 


\section{FUNDING}

This work was supported by Beijing Natural Science Foundation (Nos. 5192001; 5142003) and National Natural Science Foundation of China (Nos. 31671555; 31300958).

\section{REFERENCES}

1. Quirk SM, Porter DA, Huber SC, Cowan RG. Potentiation of Fasmediated apoptosis of murine granulosa cells by interferon-gamma, tumor necrosis factor-alpha, and cycloheximide. Endocrinology. (1998) 139:4860-9. doi: 10.1210/endo.139.12.6353

2. Chen Q, Yano T, Matsumi H, Osuga Y, Yano N, Xu J, et al. Cross-talk between Fas/Fas ligand system and nitric oxide in the pathway subserving granulosa cell apoptosis: a possible regulatory mechanism for ovarian follicle atresia. Endocrinology. (2005) 146:808-15. doi: 10.1210/en.2004-0579

3. Hsueh AJ, Billig H, Tsafriri A. Ovarian follicle atresia: a hormonally controlled apoptotic process. Endocr Rev. (1994) 15:707-24. doi: 10.1210/edrv-15-6-707

4. Hsu SY, Hsueh AJ. Hormonal regulation of apoptosis an ovarian perspective. Trends Endocrinol Metab. (1997) 8:207-13. doi: 10.1016/S1043-2760(97)00036-2

5. Jiang JY, Cheung CK, Wang Y, Tsang BK. Regulation of cell death and cell survival gene expression during ovarian follicular development and atresia. Front Biosci. (2003) 8:d222-37. doi: 10.2741/949

6. Hirshfield AN. Development of follicles in the mammalian ovary. Int Rev Cytol. (1991) 124:43-101. doi: 10.1016/S0074-7696(08)61524-7

7. Zhang C, Wang X, Wang Z, Niu W, Zhu B, Xia G. Effect of different culture systems and 3, 5, 3'-triiodothyronine/follicle-stimulating hormone on preantral follicle development in mice. PLoS ONE. (2013) 8:e61947. doi: 10.1371/journal.pone.0061947

8. Zhang C, Guo L, Zhu B, Feng Y, Yu S, An N, et al. Effects of 3, 5, 3'triiodothyronine $(\mathrm{t} 3)$ and follicle stimulating hormone on apoptosis and proliferation of rat ovarian granulosa cells. Chin J Physiol. (2013) 56:298-305. doi: 10.4077/CJP.2013

9. Liu J, Tian Y, Ding Y, Heng D, Xu K, Liu W, et al. Role of CYP51 in the regulation of T3 and FSH-induced steroidogenesis in female mice. Endocrinology. (2017) 158:3974-87. doi: 10.1210/en.2017-00249

10. Kim RJ, Nam JS. OCT4 expression enhances features of cancer stem cells in a mouse model of breast cancer. Lab Anim Res. (2011) 27:147-52. doi: 10.5625/lar.2011.27.2.147

11. Sterneckert J, Hoing S, Scholer HR. Concise review: Oct4 and more: the reprogramming expressway. Stem Cells. (2012) 30:15-21. doi: $10.1002 /$ stem.765

12. Shi G, Jin Y. Role of Oct4 in maintaining and regaining stem cell pluripotency. Stem Cell Res Ther. (2010) 1:39. doi: 10.1186/scrt39

13. Takahashi K, Yamanaka S. Induction of pluripotent stem cells from mouse embryonic and adult fibroblast cultures by defined factors. Cell. (2006) 126:663-76. doi: 10.1016/j.cell.2006.07.024

14. Kaufhold S, Garban H, Bonavida B. Yin Yang 1 is associated with cancer stem cell transcription factors (SOX2, OCT4, BMI1) and clinical implication. J Exp Clin Cancer Res. (2016) 35:84. doi: 10.1186/s13046-016-0359-2

15. Jeong JK, Lee JH, Moon JH, Lee YJ, Park SY. Melatonin-mediated beta-catenin activation protects neuron cells against prion protein-induced neurotoxicity. J Pineal Res. (2014) 57:427-34. doi: 10.1111/jpi.12182

16. Pesce M, Wang X, Wolgemuth DJ, Scholer H. Differential expression of the Oct-4 transcription factor during mouse germ cell differentiation. Mech Dev. (1998) 71:89-98. doi: 10.1016/S0925-4773(98)00002-1

17. Kehler J, Tolkunova E, Koschorz B, Pesce M, Gentile L, Boiani M, et al. Oct4 is required for primordial germ cell survival. EMBO Rep. (2004) 5:1078-83. doi: 10.1038/sj.embor.7400279

18. Bagheripour N, Zavareh S, Ghorbanian MT, Paylakhi SH, Mohebbi SR. Changes in the expression of OCT4 in mouse ovary during estrous cycle. Vet Res Forum. (2017) 8:43-8.

19. Monti M, Redi C. Oogenesis specific genes (Nobox, Oct4, Bmp15, Gdf9, Oogenesin 1 and Oogenesin2) are differentially expressed during natural and
And this project was also supported by Scientific Research Program of Beijing Municipal Commission of Education (KM201610028011). The funders had no role in study design, data collection and analysis, decision to publish, or preparation of the manuscript. gonadotropin-induced mouse follicular development. Mol Reprod Dev. (2009) 76:994-1003. doi: 10.1002/mrd.21059

20. Monti M, Garagna S, Redi C, Zuccotti M. Gonadotropins affect Oct-4 gene expression during mouse oocyte growth. Mol Reprod Dev. (2006) 73:685-91. doi: $10.1002 / \mathrm{mrd} .20471$

21. Ahmed NS, Ghatak S, El Masry MS, Gnyawali SC, Roy S, Amer M, et al. Epidermal E-cadherin dependent beta-catenin pathway is phytochemical inducible and accelerates anagen hair cycling. Mol Ther. (2017) 25:2502-12. doi: 10.1016/j.ymthe.2017.07.010

22. Ke X, Yuan Y, Guo C, Yang Y, Pu Q, Hu X, et al. MiR-410 induces stemness by inhibiting Gsk3beta but upregulating beta-catenin in non-small cells lung cancer. Oncotarget. (2017) 8:11356-71. doi: 10.18632/oncotarget.14529

23. Fan HY, O'Connor A, Shitanaka M, Shimada M, Liu Z, Richards JS Beta-catenin (CTNNB1) promotes preovulatory follicular development but represses LH-mediated ovulation and luteinization. Mol Endocrinol. (2010) 24:1529-42. doi: 10.1210/me.2010-0141

24. MacDonald BT, Tamai $\mathrm{K}$, $\mathrm{He} \mathrm{X}$. Wnt/beta-catenin signaling: components, mechanisms, and diseases. Dev Cell. (2009) 17:9-26. doi: 10.1016/j.devcel.2009.06.016

25. Hardt SE, Sadoshima J. Glycogen synthase kinase-3beta: a novel regulator of cardiac hypertrophy and development. Circ Res. (2002) 90:1055-63. doi: 10.1161/01.RES.0000018952.70505.F1

26. Shakoori A, Ougolkov A, Yu ZW, Zhang B, Modarressi MH, Billadeau DD, et al. Deregulated GSK3beta activity in colorectal cancer: its association with tumor cell survival and proliferation. Biochem Biophys Res Commun. (2005) 334:1365-73. doi: 10.1016/j.bbrc.2005.07.041

27. Lin J, Yu J, Zhao J, Zhang K, Zheng J, Wang J, et al. Fucoxanthin, a marine carotenoid, attenuates beta-amyloid oligomer-induced neurotoxicity possibly via regulating the PI3K/Akt and the ERK pathways in SH-SY5Y cells. Oxid Med Cell Longev. (2017) 2017:6792543. doi: 10.1155/2017/67 92543

28. Wang $\mathrm{X}$, Zhao L. Calycosin ameliorates diabetes-induced cognitive impairments in rats by reducing oxidative stress via the PI3K/Akt/GSK3beta signaling pathway. Biochem Biophys Res Commun. (2016) 473:428-34. doi: 10.1016/j.bbrc.2016.03.024

29. Ding Y, Tian Y, Guo M, Liu J, Heng D, Zhu B, et al. Regulation of glucose transport by thyroid hormone in rat ovary. Cell Tissue Res. (2016) 366:455-66. doi: 10.1007/s00441-016-2453-3

30. Zhang C, Xia G, Tsang BK. Interactions of thyroid hormone and FSH in the regulation of rat granulosa cell apoptosis. Front Biosci. (2011) 3:1401-13. doi: $10.2741 / \mathrm{e} 342$

31. Livak KJ, Schmittgen TD. Analysis of relative gene expression data using realtime quantitative PCR and the 2(-Delta Delta C(T)) method. Methods. (2001) 25:402-8. doi: 10.1006/meth.2001.1262

32. Tian Y, Ding Y, Liu J, Heng D, Xu K, Liu W, et al. NO-mediated regulation of GLUT by T3 and FSH in rat granulosa cells. Endocrinology. (2017) 158:1898915. doi: 10.1210/en.2016-1864

33. Patel H, Bhartiya D, Parte S, Gunjal P, Yedurkar S, Bhatt M. Follicle stimulating hormone modulates ovarian stem cells through alternately spliced receptor variant FSH-R3. J Ovarian Res. (2013) 6:52. doi: 10.1186/1757-2215-6-52

34. Mirakhori F, Zeynali B, Tafreshi AP, Shirmohammadian A. Lithium induces follicular atresia in rat ovary through a GSK-3beta/beta-catenin dependent mechanism. Mol Reprod Dev. (2013) 80:286-96. doi: 10.1002/mrd.22163

35. Parakh TN, Hernandez JA, Grammer JC, Weck J, Hunzicker-Dunn M, Zeleznik AJ, et al. Follicle-stimulating hormone/cAMP regulation of aromatase gene expression requires beta-catenin. Proc Natl Acad Sci USA. (2006) 103:12435-40. doi: 10.1073/pnas.0603006103

36. Mao L, Dauchy RT, Blask DE, Slakey LM, Xiang S, Yuan L, et al. Circadian gating of epithelial-to-mesenchymal transition in breast cancer cells via 
melatonin-regulation of GSK3beta. Mol Endocrinol. (2012) 26:1808-20. doi: 10.1210/me.2012-1071

37. Takeda K, Takemoto C, Kobayashi I, Watanabe A, Nobukuni Y, Fisher DE, et al. Ser298 of MITF, a mutation site in Waardenburg syndrome type 2, is a phosphorylation site with functional significance. Hum Mol Genet. (2000) 9:125-32. doi: $10.1093 / \mathrm{hmg} / 9.1 .125$

38. Suarez MI, Uribe D, Jaramillo CM, Osorio G, Perez JC, Lopez $\mathrm{R}$, et al. Wnt/beta-catenin signaling pathway in hepatocellular carcinomas cases from Colombia. Ann Hepatol. (2015) 14:64-74. doi: 10.1016/S1665-2681(19)30802-6

39. Sun Y, Song D, Wang M, Chen K, Zhang T. alpha7 nicotinic acetylcholine receptor agonist attenuates the cerebral injury in a rat model of cardiopulmonary bypass by activating the Akt/GSK3beta pathway. Mol Med Rep. (2017) 16:7979-86. doi: 10.3892/mmr.2017.7600

40. Yothaisong $S$, Thanee $M$, Namwat $N$, Yongvanit $P$, Boonmars $T$, Puapairoj A, et al. Opisthorchis viverrini infection activates the $\mathrm{PI} 3 \mathrm{~K} / \mathrm{AKT} / \mathrm{PTEN}$ and Wnt/beta-catenin signaling pathways in a Cholangiocarcinogenesis model. Asian Pac J Cancer Prev. (2014) 15:10463-8. doi: 10.7314/APJCP.2014.15.23.10463
41. Logan CY, Nusse R. The Wnt signaling pathway in development and disease. Annu Rev Cell Dev Biol. (2004) 20:781-810. doi: 10.1146/annurev.cellbio.20.010403.113126

42. Rocha RM, Lima LF, Alves AM, Celestino JJ, Matos MH, Lima-Verde IB, et al. Interaction between melatonin and follicle-stimulating hormone promotes in vitro development of caprine preantral follicles. Domest Anim Endocrinol. (2013) 44:1-9. doi: 10.1016/j.domaniend.2012.07.001

Conflict of Interest: The authors declare that the research was conducted in the absence of any commercial or financial relationships that could be construed as a potential conflict of interest.

Copyright (C) 2020 Heng, Wang, Ma, Tian, Xu, Weng, Hu, Liu and Zhang. This is an open-access article distributed under the terms of the Creative Commons Attribution License (CC BY). The use, distribution or reproduction in other forums is permitted, provided the original author(s) and the copyright owner(s) are credited and that the original publication in this journal is cited, in accordance with accepted academic practice. No use, distribution or reproduction is permitted which does not comply with these terms. 